\title{
User acceptance towards optical character recognition for international call Apps: Comparing the accuracy of the prediction by neural networks and SPSS equation
}

\author{
Faris Ahmed Alshammari, Ahmad Suhaimi Baharudin, Kamal Karkonasasi * \\ School of Computer Science, USM, 11800, Sungai Dua, Pulau Penang, Malaysia
}

\section{ART ICLE IN F O}

\section{Article history:}

Received 13 April 2017

Received in revised form

7 September 2017

Accepted 18 September 2017

\section{Keywords:}

OCR

Application of OCR

Accuracy

Neural networks

\begin{abstract}
A B S T R A C T
In the field of artificial intelligence and pattern recognition, the new innovative ideology called optical character recognition (OCR) has been prominent and most successful. In the past 50 years, the idea of machine reading has developed from the stage of a dream to the stage of reality and certainty. There are many systems variety of applications in existence that are commercially based for the operation and application of OCR. The incessant problem of a series of stages before making a successful international call is a beacon for urgent attention hence the desire for the business proposal. This idea makes use of OCR as a means of making faster international mobile apps card calls without going through the usual series of stages before the call can get through to the foreign country. The OCR was used to scan the serial digits of the prepaid card and immediately transfer it for the immediate call. The idea was found to be more appropriate, user friendly and faster than the early traditional system of making international calls.
\end{abstract}

(C) 2017 The Authors. Published by IASE. This is an open access article under the CC BY-NC-ND license (http://creativecommons.org/licenses/by-nc-nd/4.0/).

\section{Introduction}

The Understanding of the main determinants of Optical character recognition international call apps' acceptance is significant for the producer and users; our understanding of the role of users' acceptance of this information technology based apps' adoption is imperfect hence this study.

In recent years the Internet and information technology has been rising and contributing many Web-based applications as a new technique for organizations to keep hold of clients and offer them new services and goods. In order for both clients and organizations to take advantage of these applications, it is vital to scrutinize the authentic insight and main motives of people's enthusiasm to accept these technologies (Lee, 2009). The surfacing of Information technology (IT) based social media has considerably transformed the approaches that companies use to converse with customers (Lai and $\mathrm{Li}, 2005)$. IT via Social media offer a range of consumer-generated content (CGC), such as opinions, videos, news through blogs, podcasts,

\footnotetext{
* Corresponding Author.

Email Address: asasi.kamal@gmail.com (K. Karkonasasi) https://doi.org/10.21833/ijaas.2017.011.006

2313-626X/C) 2017 The Authors. Published by IASE.

This is an open access article under the CC BY-NC-ND license

(http://creativecommons.org/licenses/by-nc-nd/4.0/)
}

photos, ideas, interests social networking sites (SNS), etc. (Drury, 2008). Most researchers propose that IT via social media be considered as a welltimed and cost-effective marketing instrument which present companies with a comprehensive prospect to manipulate customer preferences and behavioural intention (Drury, 2008).

The mobile age is now recognized. The mobile devices producer can be conceited of their retailing, for instance, as within five years the figure of smartphone users has grown-up from $5 \%$ to $20 \%$. Furthermore, the statistics revealed that the mobile traffic had an average of $108 \%$ annual growth (Minhyung, 2010). This statistics information confers mobile applications and mobile services a very affluent prospect.

The acceptance and utilization of IT systems have been the topic of much research, and in this modern years, quite a lot of theories that proffer novel insights have appeared at both the individual and organizational stage, fixed in a country or a set of countries (Im et al., 2011). Each of the numerous models that have been projected in the literature has the identical dependent variable, use or intention to use, but with a variety of backgrounds to comprehend acceptance of the technology.

OCR which indicates optical character recognition is expressed as a scheme that presents a detailed alphanumerical recognition of handwritten 
or printed characters at a high technology speed by mere documents scanning. In the scheme, a scanner is used to scan documents and are transferred to the OCR systems which recognize the characters contained in the scanned documents and then translate them into an ASCII data.

As well known, there are three processing stages which include document scanning process, the recognition process, and the verifying process. The document scanning stage involves the use of a scanner to scan the printed or handwritten documents. In the course of this stage, the quality of the scanned documents relies on the scanner quality and model, hence, a good quality scanner with a high speed cum high resolution colour quality is advantageous. The second stage is the recognizing process which involves several complex algorithms, earlier loaded pattern and dictionary which are used to cross-checked the characters contained in the document as well as the corresponding editable ASCII characters machine. The third stage is the verifying process which is achieved by the involvement of human by either indiscriminately or chronologically.

In summary, Optical Character Recognition is a research field which focuses on pattern recognition, machine vision, artificial intelligence and signal processing. Often, OCR is referred to as an offline character recognition process which indicates that the method scans and recognizes the characters motionless figures. It pointed to the mechanical or electronic transformation of handwritten character images or printed text into machine code devoid of any variation.

A basic research question is whether this service is merit being used by the larger part of the populace or not.

\subsection{Research problem}

hIn the global business world, the enterprises come to a decision to invest in information technology systems for countless reasons; among the reasons are, the anxieties to cut costs, demands to produce more devoid of increasing costs, and basically to advance the quality of services or products so as to continue in business and be in good competitive advantages over other competitors.

The usual problem associating with international call apps is so numerous and it is tantamount to pain and hardship for the users because of the frustration, pain, and agony of nothing getting through to their friends, relatives, and family as early as they desired. Apart from the stress of getting a low cost and affordable international call apps card cannot be over emphasising. The bottle neck problem of a long process of making an international call which is considered a bureaucratic measure of the service provider is not an oversight. For instance, Credits card made use of the Information contained in magnetic stripes. Moderately, a large amount of information can be saved on the magnetic stripe, but particularly designed readers are required, such that the information cannot be read by humans.

For example, the commonly used International calling app has some bottleneck process which comprises the loading of prepaid call, and the long stages of making international calls. It involves first calling the access number which is the telephone number you dial to connect to the service of the provider and once connected to the service provider, you will be prompted through instruction to dial the local access number of the country before you dial the particular number you wish to call. This is considered a long process. But with this new idea of utilizing OCR, the long process will be cut short with the access number, local number, and the particular international number at once and the call will go through at once.

This Research tries to answer the following questions. What is the level of the user acceptance of the new optical character recognition international call apps? and Does the new Optical character recognition international call apps have a significant impact on the other international call apps?

\section{Literature review}

The literature review of this research study focused on the four major perspectives of the user acceptance factors. The past research studies on these factors are reviewed as all the factors stand as variables and used in the formation of hypothesis in this study.

Behavioural Intentions: Most of the entrenched models of behavioural intention theories like Technology Adoption Model (TAM) and the Theory of Reasoned Action (TRA), there were several attempts to scrutinize the factors that influence the consumers' decision on using an information technology studied ( $\mathrm{Wu}$ and Wang, 2005). In the study conducted by Fishbein and Ajzen (1975), the term "Behavioural Intention" was expressed as to portray “a person's subjective probability that he will perform some behaviour". Davis, in his own study, likewise supported this idea to give form to TAM (Zarmpou et al., 2012), which at last terminate to the "Actual System Use".

Perceived usefulness: The term "Perceived usefulness" has been considered as an instrumental construct in many of the technology models adopted so far since 1989 when Davis first used this term. It is explained as "the extent or level to which a person accepts as true that using a particular system would augment his or her job performance" (Zarmpou et al., 2012). The construct, Perceived usefulness, has been incorporated as a construct in a number of surveys for several kinds of technologies and systems, such as mobile payments (Chen, 2008), mobile commerce (Min et al., 2008) mobile data services in China (Qi et al., 2009), application frameworks (Polančič et al., 2010) eCRM (Chen et al., 2007), and generally, technology adoption 
models. In summary, the perceived usefulness of the technology concerned in each research study as stated above has positive significance on individuals' adoption intention of the technology.

Percieved ease of use: In addition to perceived usefulness, another factor of consideration is the "Perceived Ease of Use" which has been a fundamental perception in many of technology adoption models. This is expressed as "the degree or extent to which a person thinks that utilising a particular system would be free of effort" (Zarmpou et al., 2012). This has been integrated as a construct in a number of research studies for diverse types of technologies and systems. Good examples are mobile data services in Qi et al. (2009), application frameworks (Polančič et al., 2010), and generally new technologies (Wu and Wang, 2005). In all the mentioned research studies, the perceived ease of use of the technology has a direct positive consequence on the behavioural intention to use specific technology studied every time.

Innovativeness: The word Innovativeness in Information Technology is expressed as the "keenness or eagerness of an individual to try out any new information technology" (Flynn and Goldsmith, 1993). In another perspective in the field of technology acceptance, innovation is considered to mean the degree of interest in trying a new thing, a new concept, or novel product or service. Innovativeness as a personality trait has been linked with technology acceptance in earlier studies as an incorporated factor beside optimism, discomfort, and insecurity in the framework of the Technology Readiness Index (TRI) theory (Walczuch et al., 2007). A renown person with the knowledge of an innovation, and are considered as competent technically, suggested a direct positive effect of innovativeness on perceived ease of use (Mun et al., 2006). In addition, Walczuch et al. (2007) hypothesized that innovativeness has a positive effect on perceived ease of use and perceived usefulness concerning the acceptance procedure of IT from service employees. Kuo and Yen (2009), likewise, study the relationship of innovativeness with perceived ease of use and perceived usefulness. The result of the study revealed that innovativeness has a positive influence on the perceived ease of use of $3 \mathrm{G}$ mobile value-added services, while the effect on the perceived usefulness of $3 \mathrm{G}$ mobile value-added services remained insignificant. The study conducted by $\mathrm{Lu}$ et al. (2005) on the impact of personal innovativeness and social influence on wireless internet services revealed that there was no direct significant influence on users' intention to accept the wireless internet services via their mobile devices (Lu et al., 2005). Innovativeness was also investigated as a factor influencing the use of the Internet (Lam et al., 2008). Chen and Tong (2003) discussed the significance of innovation in the mobile telecom industry. Meanwhile, Sulaiman et al. (2006) demonstrated that personal innovativeness replicate on the acceptances' intention of mobile banking in Malaysia.

Trust: In the past studies, trust has been considered a significant factor in control consumers' behaviour in the direction of a specific technology, most importantly, when it comes to cases of indecisive environments, such as e-commerce (Androulidakis and Androulidakis, 2005). It was observed that trust should also be investigated as a driving factor in the field of mobile commerce (Tsu et al., 2009). In the general opinion, Mobile commerce is prone to the superior danger of insecurity than e-commerce and as a result, the value of the trust is relatively higher in $\mathrm{m}$-commerce (Bhattacherjee, 2002). In the case of easy measurement of trust as a variable, there are submission in the past studies that the meaning of trust should be ascribed to such word as privacy protection permitting a user to have options on how his or her personal information is shared or used (Cho et al., 2007), or supposed trustworthiness revealing that one partner believes that the other partner possess the necessary expertise to execute a job efficiently and dependably (Pavlou, 2003). Pavlou established that "trust in e-commerce is the faith that allows consumers to cheerfully become susceptible to the online retailers after having taken into consideration the retailers' characteristics" which includes the munificence trust (benevolence) and trustworthiness (honesty, reliability, and integrity) (Misra and Wickamasinghe, 2004). Min et al. (2008) separated the unit of trust in two subentities: trust in technology and trust in service providers (Min et al., 2008). He explained that Trust in technology transmits to technical protocols, transaction standards, regulating policies, payment system and as well as security in mobile devices (Davis, 1989). Meanwhile, according to Bhattacherjee's (2002) investigation for ecommerce services, trust in service providers means aptitude, that is the user's insight of provider's competencies and knowledge prominent to the expected behavior, reliability or integrity which denote the user's perception that the service providers will hold on to a set of principles or rules of exchange satisfactory to the users during and after the exchange, and kindness which signify that the service provider is supposed to be determined to do good to the users, further than its own profit motive (Cho et al., 2007).

\section{Theoretical framework and hypothesis formulation}

The most commonly used model to examined users acceptance of technology is termed the Technology Acceptance Model (Aldas-Manzano et al., 2009). This model, TAM and similar models (e.g. TAM2, UTAUT) have been painstakingly explained in the literature. Likewise, TAM is one of the generally extensively used models in information science (Mun et al., 2006). In TAM model, there was a prediction of user acceptance of a technology 
based products or services relative to the measurement of three core constructs which are, and behavioural intention (BI), perceived usefulness (PU), perceived ease of use (PeU). Basically, the model proposes that people who have it in mind to use a certain technology end up using the technology to a larger degree compare to those that do not want to use it, Likewise, those people that find a technology helpful and uncomplicated to use will be determined to use it.

Many research studies have utilized these three constructs and their interrelations were dutifully examined, the results reveal significant support of the reliability and validity of the constructs and their fundamental relations to each other. In a metaanalysis based study of 88 journal articles, Mun et al. (2006) summarised that the PU and BI instruments were extremely reliable, and the impact of PU on BI was highly significant. It was concluded also that PeU principally influenced BI through PU. This finding is parallel to that of previous reviews by (Lee, 2009).

Nonetheless, in a number of situation constructs other than PU and PeU may play a significant influence in technology acceptance. Based on this, quite a number of research studies have established the significance of trust (TR) in user acceptance of technology, particularly in obligatory scenery (Androulidakis and Androulidakis, 2005).

The constructs PU, PeU, TR and BI symbolize the users' biased perception of the technology's usefulness, that is, how easy is the technology to use, the impacts of others, and their tendency to use the technology at any other time in the near future. Consequently, these constructs replicate both the technology in question and the more or less constant cognitive and behavioural propensity of the users of this optical character recognition international call apps technology.

Consequently, it will be a wise verdict if the same relationship between the model's constructs could also be utilized in this research study. In the constructs, the user acceptance based on the behavioural intention is included.

In respect of this theoretical framework, the hypothesis of this research study are hereby stated;

H1: Perceived Ease of Use(PeU) has a positive effect on Behavioural Intention (DV).

H2: Perceived Usefulness (PU) is a mediator of a positive effect on Perceived Ease of Use(PeU).

H3: Perceived Ease of Use (PeU) has a positive effect on Perceived Usefulness (PU) of OCRIC apps.

H4: Innovativeness(INS) is a mediator of a positive effect on Perceived Ease of Use(PeU).

H5: Trust (TR) is a mediator of a positive effect on Perceived Ease of Use(PeU).

Thus, regarding the Users behavioural intention to use the OCRIC apps, mobile services, it is hypothesized that there is a relationship between the perceived ease of use and perceived usefulness as influential factors on users' behavioural intention. Many research studies that propose adoption intention models clearly authenticate the positive significance of perceived ease of use on perceived usefulness on the subject of a variety of technology topics such as mobile commerce (Wang et al., 2008), mobile data services (Qi et al., 2009); or general technology acceptance models (Hittleman and Simon, 1997). Thus, it is rational to hypothesize that the same relationship could be integrated into this research study that focused on the User's acceptance of OCRIC apps mobile services.

\section{Methodology}

Research methodology design aims are to construct the instrument to measure, examine and analyze research questions for a likely output. According to past studies, it was concluded that it is to establish the reliability and viability of the data collected in response to the questions raised in the study devoid of any vagueness in the research study.

A literature review has simplified the opportunity to present a theoretical meaning and description of all variables in this study. By this, an establishment of precise scales for assessment of these variables was drawn and perfected.

In this research study, the target population was the international and foreign students and workers around Malaysia especially the Penang state of Malaysia. The reason is the fact that, Currently, Malaysia is enjoying an education hubs statue among the Asean countries, hence inflows of students from many Arabs and African nations as well as other Asean nations that are yet to attain this statue. Bearing this in mind, the users are all around public and private universities in Malaysia. In this research study, about 40 international students and foreigners within and around Universiti Sains Malaysia are the target sample size.

A quantitative research questionnaire based on the construct as adopted from past studies that focused on users' acceptance of technology products and services are formulated. 5 scales Likert scale was used in the formulation of the adjusted questionnaires. This was administered to the target samples which are the international student and foreigners around Universiti Sains Malaysia, Penang. They are the one that made use of various international calls apps. The questionnaire was administered by hand and not by post or email so as to ensure the adequate monitoring of the questionnaire distribution and retrievement. The questionnaire was retrieved and then gathers the data and then analyze.

In order to analyze the data, SPSS application will be used to analyze the collected data. In this study, we aim to implement the descriptive analysis, correlation analysis, and regression analysis. To examine the collected data to check the data integrity and find the relationship among collected variables. Moreover, regression analysis will examine the user intention toward using my 
application, this helpful to track our target customer in the target market. In this study, we aim to optimize the prediction accuracy of regression analysis by using Artificial Neural Network (ANN). The ANN plays a vital role in the prediction area.

For the purpose of data collection, a quantitative research questionnaire based on the construct as adopted from past studies that focused on users' acceptance of technology products and services are formulated. 5 scales Likert scale was used in the formulation of the adjusted questionnaires. This was administered to the target samples which are the international student and foreigners around Universiti Sains Malaysia, Penang. They are the one that made use of various international calls apps. The questionnaire was administered by hand and not by post or email so as to ensure the adequate monitoring of the questionnaire distribution and retrievement. The questionnaire was retrieved and then gathers the data and then analyze.

\section{Results and analysis}

Statistical Package for the Social Science, SPSS was used to test the hypothesis of the research study. The software tested the covariance structure and relationship among the variables.

The demographic profile of all the respondents' shows that most of the respondents are of the age bracket 26yrs to 30yrs with about 33\% and this is closely followed by the respondents of age bracket $31-35 y r s$, they are of $26 \%$. The least age bracket of the respondents are 46yrs and above with 3\%. This is true of the profile because most of the respondents are postgraduate students of Universiti Sains Malaysia. In term of gender, most respondents are male; they are $60 \%$ compare to females that are $40 \%$. In the actual fact, most of the foreign postgraduate students in Universiti Sains Malaysia are male, only a few of them are here with their family. The married respondents are fewer compared to the single, the married are $30 \%$ while the singles are $70 \%$.

In term of education qualification, the respondents are more of Master degree students; they are of $63 \%$ compared to $27 \%$ of Ph.D. students. The respondents' year of stay in Malaysia so far reflected the duration of studies of most of the respondents, 1-5yrs has the highest percentage of $83 \%$ compared to $6-10$ yrs which has $27 \%$. The respondents' religion profile was majorly Islam with
$80 \%$, Christians have $13 \%$ and the other religion has $7 \%$.

The analysis of the variables using SPSS involves the measurement of the model. First, the measurement model is assessed. The model is examined to establish if the intended constructs can actually be assessed by the underlying latent variables. The models used in the assessment is called confirmatory Factor analysis model. This model assumes that each variable to be a distinct indicator parameter for an underlying latent construct, in such that different constructs are allowed to be intercorrelated. It is after the constructs have met the desired standard measurements that the relationship among the constructs is calculated. The second step involves the test to evaluate the strength and direction of the relationship between the constructs theoretically.

The measurement model was investigated with the use of complete FA so as to evaluate how the variables represent the constructs included in the hypothesis models, logically and systematically. The models that explain the latent constructs includes Behavioural intention BI, perceive ease of use PEoU, perceive usefulness Pus, Innovativeness Ins, and Trust, TR.

The overall goodness of fit of the constructed model was evaluated with the assistance of these common model of fit measures, non-normed fir index (NNFI), Comparative fit index (CFI), the adjusted goodness of fit index, the root mean square residual (RMR), as well as the root, mean square error of approximation (RMSEA). This is done to make use of different fit indices as taking from different categories. The research makes use of the conventional guidelines to arrive at the value of goodness of fit. The recommended value for all goodness of fit values ranges from 0.051 to 2.16 . The result of this research studies shows 0.049 to 2.14 for all the various goodness of fit. This indicates that the goodness of fit of all the construct models used in this research is within the acceptable and standard value. The $R$ value is 0.828 and the R2 is 0.685 according to the result of the SPSS value.

The mean value as shown in Table 1 shows that all the measured constructs have almost same significant value with INS having a higher mean value of 3.6. compared to the value of 3.50 for PEoU. The construct with least value is Pus with 3.24 value.

Table 1: The mean, SD of the constructed model

\begin{tabular}{ccccccccc}
\hline & $\mathrm{N}$ & Minimum & Maximum & Mean & Std. Deviation & Variance & \\
\cline { 2 - 7 } & Statistic & Statistic & Statistic & Statistic & Statistic & Statistic & Statistic & Statistic \\
\cline { 2 - 7 } dv & 30 & 1.00 & 4.75 & 3.4417 & .90421 & .818 & -1.002 & .650 \\
PEoU & 30 & 1.00 & 5.00 & 3.5083 & .92728 & .860 & -.706 & .438 \\
PUs & 30 & 1.20 & 5.00 & 3.2400 & .95035 & .903 & -.106 & -.309 \\
INS & 30 & 1.00 & 4.75 & 3.6083 & .88737 & .787 & -.795 & .872 \\
TR & 30 & 1.75 & 4.75 & 3.4250 & .83859 & .703 & -.102 & -.662 \\
Valid N (listwise) & 30 & & & & & & & \\
\hline
\end{tabular}

As depicted in Table 2, the results show that more the significant value is 0.000 , a value that is lesser than the significant standard value of 0.05 which indicate that there are significantly different 
among the measured constructs with the dependent

apps. variable of behavioral intension of the OCRIC mobile

Table 2: ANOVA of measured construct

\begin{tabular}{ccccccc}
\hline & Model & Sum of Squares & DF & Mean Square & F & Sig. \\
\hline \multirow{4}{*}{1} & Regression & 16.236 & 4 & 4.059 & 13.577 & $.000^{\mathrm{b}}$ \\
& Residual & 7.474 & 25 & .299 & & \\
& Total & 23.710 & 29 & & & \\
\hline \multicolumn{6}{c}{} & a. Dependent Variable: dv; b. Predictors: (Constant), TR, INS, PEoU, PUs
\end{tabular}

Pearson Correlation: The two-tailed Pearson correlation shows the strength of the relationship within the construct variables. Among all the variables, there is a large correlation among each one of them.

The $d v$, dependent variable has a large positive correlation with all the construct variables with $\mathrm{dv}$ correlation with Trust being the least value with 0.474 while perceive usefulness has the highest positive significant correlation. Testing process: The requirements of testing process test matrix include 7 instances of four significant variables, network object, and output matrix. The testing expression as the following:

$a=\operatorname{sim}($ network 1, test $)$;

where $\mathrm{a}=$ output result of tested values, network1 = trained network object, test $=27$ instances of three significant variables and $\operatorname{sim}=$ Network simulate function. So, the predicated values of tested instances will be stored in the variable "a".

By comparing the errors of a neural network with errors of SPSS equation results as shown in Table 3, the neural network successfully predicates 5 values from 7 tested instances. That means the neural network successfully predicates $71.96 \%$ of tested values. On another hand, the SPSS equation of three significant variables successfully predicates 4 value from 7 tested instances. That means the SPSS equation successfully predicates $56.74 \%$ of tested values, however, the difference is clear between SPSS equation and trained the neural network in predication accuracy. In this study the neural network still more accurate and better than SPSS predication equation. Any improvement in the fuzzy function will improve the accuracy of overall outcomes.

Table 3: ANOVA of measured construct

\begin{tabular}{|c|c|c|c|c|c|c|c|c|}
\hline & \multicolumn{2}{|c|}{ Original result } & \multicolumn{3}{|c|}{ Neural network } & \multicolumn{3}{|c|}{ SPSS equation 1} \\
\hline & Original result & De-fuzzy & Output & De-fuzzy & Errors & output & De-fuzzy & Errors \\
\hline 1 & 4.75 & 5 & 3.770395 & 4 & Incorrect & 4.89625 & 5 & Correct \\
\hline 2 & 3.75 & 4 & 4.37375 & 4 & Correct & 3.2923 & 3 & Incorrect \\
\hline 3 & 3.75 & 4 & 2.655932 & 3 & Incorrect & 3.1432 & 3 & Incorrect \\
\hline 4 & 4.25 & 4 & 3.710996 & 4 & Correct & 3.88735 & 4 & Correct \\
\hline 5 & 2.75 & 3 & 2.886303 & 3 & Correct & 2.7862 & 3 & Correct \\
\hline 6 & 3.25 & 3 & 2.50601 & 3 & Correct & 2.94265 & 3 & Correct \\
\hline 7 & 2.25 & 2 & 1.623343 & 2 & Correct & 2.63645 & 3 & Incorrect \\
\hline
\end{tabular}

\section{Conclusion}

The t-statistic value achieved from bootstrapping of all the construct values demonstrates that all loadings are significant at $1 \%$. Furthermore, it can also be summarized is possible to conclude that all items have loadings greater than 0.7 , internal consistency. The next step was the evaluating of the constructs' reliability, using both composite reliability (CR) and Cronbach's alpha (CA). The most usual criterion is CA, providing an estimate for the reinterned consistency of each construct and the extent to which the items represent the underlying constructs. The result shows that each construct is above the expected threshold of 0.7 , this is a proof of internal consistency.

This research study observes how the behavioral intention of users of OCRIC, perceived usefulness of the mobile services, the perceived ease of their use, innovativeness, trust co-exist in the same model forecasting the consumer behavioral intention to use OCRIC international call mobile apps services.
The results of the study proffer strong verification in support of the proposed business idea. The study results signify an important implication for practitioners, most importantly application developers, services content providers, scholars and mobile services manufacturers that are eager on examining OCRIC technology acceptance and the usage of the apps mobile services usage. This study has both theoretical and managerial implications.

The theoretical implication of this research study lies in the test conducted on the possible impact of the aforesaid constructs variables on the behavioral intention of the users of the OCRIC, as well as probable influential relationships between the variables. The results attained in this research study of concluding that there is an enhanced acceptance model of OCRIC apps mobile services. Although not all the initial hypothesis is verified yet, it could be established that Perceived ease of use does not seem to have a strong effect on behavioral intention. This complies with the pre-implementation TAM models as suggested by Davis (1989). 
The managerial implication involves the assistance rendered by the practitioner to assess their development decisions on the basis of emphasis placed on different factors which affect the acceptance and adoption of the OCRIC mobile apps services. The result of this research study could be used by companies and organizations involved in the mobile apps services development, mobile commerce investment and marketing firm could also use this as a consultancy tool while planning and organizing their marketing strategy.

In conclusion, this study reveals clearly that OCRIC mobile apps can be generally accepted by the users of mobile apps and it will surely attain target market value.

\section{Acknowledgement}

The authors would like to thank Universiti Sains Malaysia (USM) as this research has been supported from the Research University Grant (RUI) [Account Number: 1001/PKOMP/811251] and from Incentive Grant Graduate on Time (GOT) [Account Number: 1001/PKOMP/823131] from the Universiti Sains Malaysia.

\section{References}

Aldas-Manzano J, Ruiz-Mafe C, and Sanz-Blas S (2009). Exploring individual personality factors as drivers of $\mathrm{m}$-shopping acceptance. Industrial Management and Data Systems, 109(6): 739-757.

Androulidakis N and Androulidakis I (2005). Perspectives of mobile advertising in Greek market. In the International Conference on Mobile Business, IEEE, Sydney, Australia: 441444. https://doi.org/10.1109/ICMB.2005.78

Bhattacherjee A (2002). Individual trust in online firms: Scale development and initial test. Journal of Management Information Systems, 19(1): 211-241.

Chen J and Tong L (2003). Analysis of mobile phone's innovative will and leading customers. Science Research Management, 24(3): 25-31.

Chen L (2008). A model of consumer acceptance of mobile payment. International Journal of Mobile Communications, 6(1): 32-52.

Chen Q, Chen HM, and Kazman R (2007). Investigating antecedents of technology acceptance of initial eCRM users beyond generation $\mathrm{X}$ and the role of self-construal. Electronic Commerce Research, 7(3): 315-339.

Cho DY, Kwon HJ, and Lee HY (2007). Analysis of trust in internet and mobile commerce adoption. In the $40^{\text {th }}$ Annual Hawaii International Conference on System Sciences, IEEE, Waikoloa, USA: 50-50. https://doi.org/10.1109/HICSS.2007. 76

Davis D (1989). Perceived usefulness, perceived ease of use and user acceptance of information technology. Management Information Systems Quarterly, 13(3): 319-340.

Drury G (2008). Social media: Should marketers engage and how can it be done effectively?. Journal of Direct, Data and Digital Marketing Practice, 9(3): 274-277.

Fishbein M and Ajzen I (1975). Belief, attitude, intention and behavior: An introduction to theory and research. AddisonWesley, Boston, USA.
Flynn L and Goldsmith R (1993). A validation of the Goldsmith and Hofacker innovativeness scale. Educational and Psychological Measurement, 53(4): 1105-1116.

Hittleman DR and Simon AJ (1997). Interpreting educational research: An introduction for consumers of research. Prentice-Hall, Inc., Upper Saddle River, USA.

Im I, Hong S, and Kang MS (2011). An international comparison of technology adoption: Testing the UTAUT model. Information and Management, 48(1): 1-8.

Kuo Y and Yen S (2009). Towards an understanding of the behavioral intention to use $3 \mathrm{G}$ mobile value-added services. Computers in Human Behavior, 25(1): 103-110.

Lai VS and Li H (2005). Technology acceptance model for internet banking: an invariance analysis. Information and Management, 42(2): 373-386.

Lam S, Chiang J, and Parasuraman A (2008). The effects of the dimensions of technology readiness on technology acceptance: An empirical analysis. Journal of Interactive Marketing, 22(4): 19-39.

Lee MC (2009). Factors influencing the adoption of Internet banking: An integration of TAM and TPB with perceived risk and perceived benefit. Electronic Commerce Research and Applications, 8(3): 130-141.

Lu J, Yao J, and Yu C (2005). Personal innovativeness, social influences and adoption of wireless internet services via mobile technology. Journal of Strategic Information Systems, 14(3): 245-268.

Min Q, Ji S, and Qu G (2008). Mobile commerce user acceptance study in China: A revised UTAUT model. Tsinghua Science and Technology, 13(3): 257-264.

Minhyung K (2010). The mobile big bang. SERI Quarterly, 3(4): 79-85.

Misra S and Wickamasinghe N (2004). Security of a mobile transaction. Electronic Commerce Research, 4(4): 359-372.

Mun YY, Jackson JD, Park JS, and Probst JC (2006). Understanding information technology acceptance by individual professionals: Toward an integrative view. Information and Management, 43(3): 350-363.

Pavlou P (2003). Consumer acceptance of electronic commerce: Integrating trust and risk with the technology acceptance model. International Journal of Electronic Commerce, 7(3): 101-134.

Polančič G, Heričko M, and Rozman I (2010). An empirical examination of application frameworks success based on technology acceptance model. Journal of Systems and Software, 83(4): 574-584.

Qi J, Li L, Li Y, and Shu H (2009). An extension of technology acceptance model: Analysis of the adoption of mobile data services in China. Systems Research and Behavioral Science, 26(3): 391-407.

Sulaiman A, Jaafar NI, and Mohezar S (2006). An overview of mobile banking adoption among the urban community. International Journal of Mobile Communications, 5(2): 157168.

Tsu Wei T, Marthandan G, Yee-Loong Chong A, Ooi KB, and Arumugam S (2009). What drives Malaysian m-commerce adoption? An empirical analysis. Industrial Management and Data Systems, 109(3): 370-388.

Walczuch R, Lemmink J, and Streukens S (2007). The effect of service employees' technology readiness on technology acceptance. Information and Management, 44(2): 206-215.

Wang C, Lo S, and Fang W (2008). Extending the technology acceptance model to mobile telecommunication innovation: The existence of network externalities. Journal of Consumer Behaviour, 7(2): 101-110. 
Wu J and Wang S (2005). What drives mobile commerce? An empirical evaluation of the revised technology acceptance model. Information and Management, 42(5): 719-729.
Zarmpou T, Saprikis V, Markos A, and Vlachopoulou M (2012). Modeling users' acceptance of mobile services. Electronic Commerce Research, 12(2): 225-248. 